\title{
PRESENTE Y FUTURO GNÓMICO EN PLAUTO
}

The author of this study discusses the atemporal uses of the verb in Latin from the gnomic perspective of the use of the Present-tense and the Future in Plautus. She also focuses on the fact that the gnomic Perfect does not appear until Catullus' Poem 64, since the plautine style is more developped on the level of "parole» than on the level of «langue». The indifferent use of gnomic present/future in maxims, assertions and proverbs makes us think of a contextual neutralizaction, and, consequently, of a stylistic and literary variation in Plautus.

Según Baratin «desde Prisciano, el verbo aparece cargado de un valor particular, en la medida en que los verbos llegan a ser centro de la noción de la transitividad. Es a partir de este papel de la transición como los verbos han terminado por ser elegidos, en un grado último de esta evolución, como el centro de la noción, en tanto que constituyen el medio de la transición' ' ${ }^{\prime}$. La lingüística contemporanea, por su parte, ha sistematizado el papel del verbo en la frase y su noción como centro de la frase, llegando a afirmar Charpin que «sobre el plano sintáctico, la forma verbal aparece, esencialmente, como el nudo del enunciado. Todas las funciones se organizan según el papel del verbo; el verbo, pues, constituye el centro sintáctico de la frase» ${ }^{2}$.

\section{LOS TIEMPOS DEL VERBO LATINO}

Basándose en el estudio de Pinkster «Tempus, Aspect and Aktionsart" ${ }^{3}$, que analiza y resume las aportaciones que se han realizado sobre el tema desde 1961 a 1981 , los tiempos del verbo latino han sido, por

\footnotetext{
I M. Baratin, Priscien et la constitution d'une syntaxe. París 1972, p. 272.

2 F. Charpin, L'idée de phrase grammaticale et son expression en latin, Lille 1977, p. 471.
} 
lo general, considerados bien bajo un punto de vista aspectual-temporal, si autores como Meillet y Perrot ${ }^{4}$ siguen la división que establece la escuela varronista en infectum/perfectum - tres tiempos para el infectum y tres para el perfectum - o bien se basan en la temporalidad o en las relaciones de esta temporalidad. Tal es el caso de Serbat y Pinkster, quedando establecida la temporalidad del verbo y su representatividad en dos ejes: el eje I de carácter sintagmático, anterioridad-simultaneidad-posterioridad, a quien cruza paradigmáticamente el pasado-presente y futuro; en el eje II, que desarrolla el anterior, el perfecto tiene su correspondencia con la anterioridad y el imperfecto con el pasados.

No obstante, como lo gnómico puede tener lugar bien en el presente, en el perfecto o en el futuro, es necesario delimitar los valores de los tres tiempos verbales y al mismo tiempo tratar de profundizar en cuál o cuáles puede o pueden ser los motivos que impulsan a la atemporalidad en estos tres tiempos del verbo latino - además de saber que las verdades generales o de experiencia son válidas para todo tiempo.

El presente, en palabras de Serbat, «es la forma no temporal del verbo" ${ }^{6}$. De hecho, el presente posee valores numerosos y contradictorios: valores no temporales de presente gnómico y presente de costumbre, que aparentemente nada tienen que ver con los valores de actual-pasado y futuro, los cuales, en un principio, debieran excluirse unos a otros; «mientras que - como dice Touratier - es imposible establecer de forma satisfactoria y rigurosa la unidad semántica de estos diferentes valores, con la ayuda de las teorías psicologizantes de la gramática tradicional o fonologizante de la lingüística moderna" ${ }^{7}$, parece muy posible atribuir estos valores al contexto lingüístico o a las pautas enunciativas. En una enunciación del discurso en que el presente corresponde a un proceso actual más o menos lejano. Es en estos procesos donde se encuentran los valores atemporales del presente, cuando se trata de una verdad de experiencia o una proposición puramente abstracta. 319.

${ }^{3}$ H. Pinkster, "Tempus, Aspect and Aktionsart», ANRW 29 II, 1983, pp. 270-

4 A. Meillet, "Sur les caractères du verbe», Revue de Philosophie 39, 1920, p. 1; A. Meillet, Linguistique historique et linguistique générale, París 1948, pp. 149-158; J. Perrot, "Les faits d'aspects dans les langues classiques», IL 13, 1961, pp. 109-118 y $154-163$.

Sinkster, op. cit., pp. 276-277; para los valores del pretérito perfecto y del imperfecto, véase J. L. Moralejo, "Praeteritum Perfectum», en Homenaje a M. Fernández-Galiano, EClás 88, 1983, pp. 137-147.

6 G. Serbat, «Les temps du verbe en latin, I: Le présent de l'indicatif», REL 53, 1975 , p. 389.

${ }^{7} \mathrm{Ch}$. Touratier, "Analyse d'un système verbal. Les morphèmes grammaticaux du verbe latin", en H. Pinkster (ed.), Latin Linguistics and Linguistic Theory, Amsterdam 1983, p. 268. 
El futuro es "fundamentalmente prospectivo» ${ }^{8}$, si bien puede aplicarse a "un momento determinado del devenir" ${ }^{9}$, pero también puede formar parte de un proceso que quiere ver que se produzca o como susceptible de producirse. Los gramáticos establecen además un futuro potencial ${ }^{10}$, en casos como el de Plauto, Persa 645: haec erit bono genere nata, "ella será de buena familia" - porque no sabe mentir-, o un futuro gnómico - también denominado acrónico "- en Mostellaria 1041: qui homo timidus erit in rebus dubiis, nauci non erit, "el hombre que sea (lit. sea en un futuro o será) un cobarde en los asuntos de índole dudosa, no valdrá ni una cesta».

En relación con el perfecto, Mariner ${ }^{12}$ con respecto a la postura de Bergsland, al considerar el imperfectiuum $=$ infectum y el perfectiuum $=$ perfectum, cuestionaba si estaría muy desencaminado el buscar en esta noción de anterioridad la fundamental en los tiempos del sistema de perfecto, con respecto al presente, a que cada uno se opone.

El perfecto puede significar un "passé accompli» por ejemplo para Serbat ${ }^{13}$ o un «accompli pur et simple», en palabras de Poirier ${ }^{14}$. Es decir, un proceso que llega a su término, lo que significa que puede explicarse temporalmente. Cuando el perfecto está explícita o implícitamente ligado a la situación actual, significa simplemente que la acción está acabada y es el contexto o la situación enunciada quien localiza en el presente esta acción acabada.

Bajo la perspectiva diacrónica de la historia de la lengua latina, el perfecto gnómico no hace su aparición hasta el poema 64 de Catulo ${ }^{15}$. El poema que narra las bodas de Tetis y Peleo; el poeta, al llegar a la descripción del cobertor del lecho nupcial, relata el amor desgraciado de Ariadna por Teseo. En los versos 143-148, Ariadna lanza reproches vanos, sobre la infidelidad masculina, a las naves de Teseo que se alejan de Creta:

${ }^{8}$ G. Serbat, "Les temps du verbe en latin, II: Le futur de l'indicatif», $R E L 53$, 1975 , p. 403.

A. Ernout-F. Thomas, Syntaxe latine, París 1959, p. 225.

10 J. B. Hofmann-A. Szantyr, Syntax und Stilistik, Munich 1965, p. 310; Ch. E. Bennett, Syntax of Early Latin, $1966(=1910)$, p. 45; H. Pinkster, Latijnse Syntaxis en Semantiek, Amsterdam 1984, p. 290.

"Véase Bennett, op. cit., p. 44.

12 S. Mariner, "La oposición infectum/perfectum ante un análisis estructural", Actas del I C.E.E.Clás. Madrid 1958, p. 532.

${ }_{13}$ G. Serbat, "Le parfait de l'indicatif latin», REL 54, 1976, p. 336.

$14 \mathrm{M}$. Poirier, "Le parfait de l'indicatif latin: un passé accompli o un accompli pur et simple?", REL 56, 1978, p. 369.

is R. Kühner, Ausführliche Grammatik der lateinischen Sprache, Darmstadt 1974, p. 137. 
Nunc iam nulla uiro iuranti femina credat nulla uiri speret sermones esse fidelis; quis dum aliquid cupiens animus praegestit apisci, nil metuunt iurare, / nihil promittere parcunt: sed simul ac cupidae mentis satiata libido est, dicta nil metuere, / nihil periuria curant.

La realización en el presente, como verdad de carácter general, se actualiza más aún por medio de los modificadores temporales nunc iam, dum y simul ac. Este último cierra los dos últimos versos, donde hallamos el perfecto gnómico metuere, a los presentes que aparecen a lo largo de todo el texto. A la vez que estilísticamente Catulo usa de la uariatio en nil metuunt iurare / dicta nil metuere.

\section{Presente y futuro gnómico en Plauto}

Es doctrina communis que Plauto, a lo largo de sus veintiuna comedias, inserta numerosos proverbios, «hasta tal punto que nuestro cómico es una de las principales fuentes de la paremiografia romana» ${ }^{16}$. Estas verdades generales o proverbiales se realizan, en su mayor parte, en el tiempo presente y abarcan un amplio espectro que va desde los contextos de exhortación o experiencia: refranes populares, proverbios del mundo campesino... hasta el mundo en torno al que gira el hombre romano: dioses, siervos, patrones y clientes, matronas y meretrices; el amor... y, finalmente, el "eterno femenino" expresado, la mayoría de las veces, en el tiempo futuro. Veamos, pues, algunos ejemplos ${ }^{17}$ :

a) Contextos de exhortación o experiencia:

Am. 35-36: lo justo e injusto

nam iniusta ab iustis impetrari non decet, iusta autem ab iniustis petere insipientia est.

As. 834: la modestia en el joven

decet uerecundum esse adulescentem.

${ }^{16}$ A. Fontán, Humanismo Romano, Madrid 1974, p. 40. 1966.

17 Cito por la edición de W. M. Lindsay, vol. I, Oxford 1968; vol. II, Oxford 
Ep. 113: la amistad ${ }^{18}$

is est amicus, qui in re dubia re iuuat.

Mer. 319: la cualidad del ser humano

humanum amarest, humanum autem ignoscere est.

St. 300: la soberbia

secundas fortunas decent superbiae.

Tri. 367: la sabiduría

non aetate, uerum ingenio apiscitur sapientia.

Se puede observar en los ejemplos anteriores el uso preferente por el verbo sum, seguido del verbo decet, en los contextos exhortativos o de experiencia.

b) Refranes populares:

Aul. 195: el pan y la piedra altera manu fert lapidem, panem ostentat altera.

$C u$. 53: la llama y el humo semper tu scito, flamma fumo est proxuma.

Mo. 791: soplar y sorber imposible es simul flare sorbereque hau factu facilest.

Pers. 41: pedir lo imposible quod tu me rogas; nam tu aquam a pumici nunc postulas/.

18 Sobre la amistad, véase el artículo de C. Castillo, «Los amigos en la comedia romana", en Homenaje a M. Fernández-Galiano, EC 88, 1983, pp. 173-182. 
Ps. 739: ser cáustico

ecquid is homo habet aceti in pectore?

En los refranes populares es utilizado en menor medida el verbo sum frente a los infinitivos; en alguna ocasión los refranes están actualizados en su temporalidad por medio de nunc o simul.

c) Proverbios campesinos:

As. 495: el lobo y el hombre

lupus est homo homini, non homo ${ }^{19}$.

Men. 247: buscar lo imposible

in scirpo nodum quaeris.

Mo. 559: la dificultad de vencer

tam facile uinces quam pirum uolpes comest.

Poen. 871: el volar sin alas

sine pinnis uolare hau facilest: meae alae pinnas non habent/.

Ps. 747: es escurridizo como una anguila

quid quom manufesto tenetur? anguillast, elabitur/.

Tru. 149: la tierra no da dinero ${ }^{20}$

non aruos hic, sed pascuost ager: si arationes

habituris, qui arari solent, ad pueros ire meliust.

Los proverbios campesinos, que tratan fundamentalmente sobre la fauna, flora, cultivo de los campos, etc., y en los que se toma como símil comparativo a la tierra o a los animales, suelen expresarse a través

19 El mismo proverbio en Sen., Epp. 103.

20 Para el estudio de este verso, véase A. Fontán, op. cit., pp. 36-40. 
del verbo sum, con comparación explícita o implícita; al igual que los verbos apropiados a la naturaleza del animal en cuestión: la zorra comest y la anguila elabitur.

d) El Amor: el mal de amores:

Cis. 69, 72

nam ecastor Amor est melle et felle est fecundissimus/. perfidiosus est Amor.

e) Los dioses:

Ba. $816-817$

quem di diligunt / adulescens moritur ${ }^{21}$.

Pero también es cierto que pueden jugar con los hombres, como en Cap. 22:

enim uero di nos quasi pilas homines habent.

f) Los esclavos:

Mil. 477: los esclavos hablan demasiado

mussitabis: plus oportet scire seruom quam loqui/.

g) Patronos y clientes: no le importan al esclavo:

Mo. $\mathbf{4 0 7 - 8}$

pluma haud interest patronus an cliens probior siet/.

h) La matrona y la meretriz: tiene cada cual su papel en la sociedad romana:

${ }^{21}$ El proverbio es de Menandro; cf. Menander, ed. F. G. Allinson, Fragments from identified plays, Harvard 1964, pp. 344-345. 
Mo. 190

matronae, non meretrecium est unum inseruire amantem/.

\section{i) La mujer:}

En los versos 365/368 de Persa, Saturio habla a su hija en los siguientes términos: uirgo atque mulier nulla erit quin sit mala, pero especifica quae praeter sapiet quam placet parentibus; la respuesta de su hija no se hace esperar: uirgo atque mulier nulla erit quin sit mala, a no ser que quae reticet si quid fieri peruorse uidet. La concurrencia del presente y el futuro gnómico se repite en los versos 288-291 de Mostellaria. El diálogo se desarrolla entre la meretriz Filematio y la criada Escafe, en el momento en que la meretriz se está vistiendo y acicalando para recibir al joven Filolaques. Escafe trata de guardar la apariencia real de su señora y, a la vez, que el joven no descubra los regalos que le han hecho los otros amantes a Filematio. Habiéndole negado poco tiempo antes (v. 273) Escafe a Filematio los perfumes, alegando que mulier recte olet ubi nil olet, en el momento en que la señora le pide su opinión a la criada sobre el vestido y las joyas, Escafe contesta:

purpurata aetati occultandaest, aurum turpi mulieri. pulchra mulier nuda erit quam purpurata pulchrior.

En principio, no existe un motivo especial por el que Plauto eligiese el futuro gnómico en lugar del presente; no obstante, dentro de la atemporalidad, no cabe duda de que es más temporal el futuro que el presente.

La sentencia de Persa 365, «no existirá ninguna mujer que no sea mala", la hallamos en contextos parecidos en Afranio, 7: hau facul, ut ait Pacuuius, femina inuenietur, o en Nevio, Com. 90 numquam quisquam amico amanti amica, nimis fiet fidelis, nec nimis morigera et deuota quisquam erit. Por lo tanto, cabría pensar en un refrán popular o conclusión general, verdad de experiencia, etc..., que Plauto utiliza en el momento y en el lugar oportuno de la comedia.

Asimismo, es coincidente, pero no decisorio, el hecho de que el futuro gnómico de pulchra mulier erit quam purpurata pulchrior tenga su paralelo - fundamentalmente por el septenario trocaico- en el verso 1041 de Mostellaria, en la referencia al "cobarde»: qui homo timidus erit in rebus dubiis, nauci non erit. 


\section{Conclusiones}

A) Tras el estudio del presente y del futuro gnómico en Plauto, pensamos que los usos atemporales del verbo latino en su uso gnómico de presente, futuro - $\mathrm{e}$ incluso de perfecto- vienen dados por el contexto enunciativo, cuyo verbo más frecuente es el verbo sum; que en ocasiones determinadas no parece necesaria su presencia, en función de la comprensión contextual, como por ejemplo en Tru. 885 ubi amici ibi opes, en orden a que el papel del "verbo centro de frase" ha sufrido un desplazamiento hacia los adverbios ubi-ibi, o en Mi. 660: amicus amico y Mer. 81: amantes amentes, donde adquiere relevancia el juego de palabras.

B) Creo que la razón principal que existe para que Catulo, en el poema 64 , utilice el perfecto gnómico, se debe a la influencia del aoristo gnómico griego ${ }^{22}$. El neóteros Catulo no se limita al tema griego: Ariadna y $\mathrm{Teseo}^{23}$, sino que convierte el aoristo griego en un perfecto latino, que convive con el presente; como dice Ruipérez ${ }^{24}$ "esta indiferencia al tiempo expresada por el aoristo general -en latín por un 'accompli'es propia del valor de pretérito en el sistema de la 'langue' y no una mera realización de su valor pretérito".

El perfecto latino, utilizado más en un contexto narrativo, expresando la anterioridad y, en cambio, el perfecto gnómico - también en el caso señalado de Catulo - viene a ser el que realiza en el presente las experiencias pasadas. Si bien es cierto que Plauto no utiliza el perfecto gnómico, sí lo hace con otros usos atemporales, tal es el caso de perii!, en que el oyente sentirá un proceso presente como acabado en el pasado. De acuerdo con todos estos usos, no debemos olvidar que nos encontramos en una sintaxis impresiva, en unos contextos enunciativos mucho más cercanos a la "parole» que a la «langue», lugar en que se suele desarrollar el perfecto gnómico.

C) Finalmente, en el mismo plano de atemporalidad del presente y del futuro, este último, por su propio carácter de que quiere ver un pro-

22 Utilizado por Hesíodo en Opera et dies 218: «incluso el necio aprende (lit. aprendió) con la experiencia” (ed. M. L. West, Oxford 1978, p. 105); también hallamos un perfecto gnómico en la Iliada de Homero (X 320): «y así muere (lit. murió) el holgazán como el laborioso" (ed. W. Leaf, vol. I, Amsterdam 1971, p. 344).

${ }^{23}$ La historia del abandono de Ariadna por Teseo la relata por primera vez Apolodoro en Epitome I 9; cf. A. Ruiz de Elvira, Mitología Clásica, Madrid 1982, p. 372.

${ }_{24}$ M. Ruipérez, Estructura de Aspectos y Tiempos del verbo griego, Salamanca 1954, pp. 97-99. 
ceso susceptible o una alta probabilidad de que se produzca, es el término marcado de la temporalidad frente al presente.

Plauto utiliza indistintamente el presente / futuro en sentencias, aseveraciones, refranes, etc..., lo que nos hace encontrarnos ante una neutralización contextual que, a su vez, comporta una uariatio estilística y literaria del autor. Los refranes o clichés en ocasiones le vienen dados a Plauto por la influencia literaria, como en $\mathrm{Ba}$. 815-816: quem di diligunt adolescens moritur, tomado de Menandro ${ }^{25}$; o bien por una consideración general de la mujer, para cuya finalidad utiliza un futuro en Persa 365-368: "no existirá ninguna mujer que no sea mala», o en $M o$. 289: «la mujer hermosa será mucho más hermosa desnuda que vestida de púrpura", pero también Plauto utiliza el presente gnómico en $R u$. 114: cuando el pescador Gripo le dice al esclavo Tracalión que las mujeres - Palestra y Ampelisca - han enmudecido ante su pregunta, el esclavo le responde: eo tacent: quia tacita bonast mulier semper quam loquens.

Virginia Bonmati SÁnchez

${ }^{25}$ Véase nota 21. 